\title{
THE ROLE OF ARTIFICIAL INTELLIGENCE RECRUITMENT AND QUALITY TO EXPLAIN THE PHENOMENON OF EMPLOYER REPUTATION
}

\author{
Sebastian KOT (D) 1, 2*, Hafezali Iqbal HUSSAIN (D) 3, 4, Svitlana BILAN (D) 5, 6 , \\ Muhammad HASEEB ${ }^{(1)}{ }^{3}$, Leonardus W. W. MIHARDJO (D) 7 \\ ${ }^{1}$ The Management Faculty, Czestochowa University of Technology, Częstochowa, Poland \\ ${ }^{2}$ College of Business and Economics, University of Johannesburg, Johannesburg, South Africa \\ ${ }^{3}$ Taylor's Business School, Taylor's University, Subang Jaya, Malaysia \\ ${ }^{4}$ University of Economics and Human Sciences in Warsaw, Warsaw, Poland \\ ${ }^{5}$ University of Economics and Innovation in Lublin, Lublin, Poland \\ ${ }^{6} \mathrm{Al}$-Farabi Kazakh National University, Almaty, Republic of Kazakhstan \\ ${ }^{7}$ Bina Nusantara University, Jalan Hang Lekir I no. 6, Senayan, Jakarta, 10270, Indonesia
}

Received 12 October 2020; accepted 28 January 2021

\begin{abstract}
The prime contribution of current research entails the explanation of role of artificial intelligence based human resource management function to determine the employer reputation among pharmaceutical industry of Indonesia. The study intends to examine the empirically investigation the role and impact of artificial intelligence-based recruitment and artificial intelligence-based quality to determine the employer reputation with mediating role of artificial intelligence adoption. The study contributes to the body of knowledge and claims to be novel in explaining the AI based HR function to explain the phenomenon of employer reputation. The study examined the empirical investigation between AI based recruitment and AI based quality to influence the AI adoption that further predicts the phenomenon of employer reputation. The study was conducted on pharmaceutical industry of Indonesia and convenience sampling was used for data collected and Smart-PLS was utilized for data analysis. The study found that AI based recruitment and quality significantly influences the AI adoption and further it influences the employer reputation. The mediation role of artificial intelligence adoption is significant where it is found that artificial intelligence mediates the relationship between artificial intelligence recruitment and employer reputation, with similar significant mediation role between artificial intelligence quality and employer reputation.
\end{abstract}

Keywords: artificial intelligence (AI), artificial intelligence recruitment (AIR), artificial intelligence quality (AIQ), artificial intelligence adoption (AIadopt), employer reputation (ER), human resource management (HRM).

JEL Classification: E24, J24, O15.

\footnotetext{
*Corresponding author. E-mail: sebacat@zim.pcz.czest.pl
} 


\section{Introduction}

The emergence of latest technologies and artificial intelligence has shaped the business practices towards digitally managed functions. The utilization of artificial intelligence to conduct business activities has taken attention due to its significant impact in business environment. The literature has expressed artificial intelligence (AI) as an umbrella of computer-based technology that serves various business functions with human like intelligent for effective decision making. The utilization of AI enables firms to create novel recognition patterns and language translation with various algorithms in global business environment to conduct business functions. The studies have been conducted to determine the role of AI in various business functions such as management, marketing, operations and supply chain management, few studies have been addressed the human resource management process including functions of HR. It has been documented in literature that firms adopt latest technological systems to conduct management functions, but parallel to adoption of technologies firms depends on traditional and non-technological methods for business management such as in HR functions including recruitment, advertisement, employees' management and relations among different participants of same businesses. The emergence of IT based systems has provided functions to conduct business processes including recruitment processes, marketing functions and financial functions that have been improved since implementation of IT based systems (Nawaz, 2019). The business functions based on electronic means such as conducted through AI based systems known as electronic HR, electronic commerce and electronic management; the latest technological based equipment facilitates business processes with accuracy, effectiveness and speed since the emergence and implementation of IT based systems well known as artificial intelligence. The previous limited studies have been discussed electronic means of managing HR such as recruitment and hiring processes that required to fulfill the current vacant position at firms (Breaugh, 2013), including those devoted to social networks usage in HRM processes (Rozsa \& Kmecová, 2020).

The current study intends to explain the human resource functions in AI perspective that influence the employees related outcomes. The study contributes to the body of knowledge by explaining the human resource functions in AI technological perspective.

The present intends to determine the relationship and influence of AI based system on employer reputation, the study intends to determine the influence of AI based recruitment and AI quality on adoption of AI based systems that determine the employers' reputation among Indonesian pharmaceutical industry.

The image of firm is referred as employer reputation that is perceived by current employees and potential workforce to work for firm as a better place to work and considered as one of attractive destination to work. The reputation of employer demonstrates the ability of firms that attract, recruit and retain talent in organization that contributes in achievement of objectives. The poor talent management and human resource practices brings negative outcomes by increase in cost of hiring, compensation cost, training cost and it creates poor reputation (Altounjy et al., 2020; Dlalisa \& Govender, 2020; Berejena et al., 2020; Auriacombe \& Sithomola, 2020; Basheka \& Auriacombe, 2020; Pachura, 2019). The various business practices adopted by firms receive various criticisms that damage the reputation of organizations among customers, business partners and employees. The poor practices have been observed 
in Amazon to criticize employees in front of their bosses, sabotage among employees, stress at workplace, and higher work pressure due to overworking demand by management. These practices considered as bad that caused poor reputation that negatively affected talent management that later cause employee turnover. The studies have been conducted to address the phenomenon of reputation at workplace that fosters the talent in organizations (Babikova \& Bucek, 2018). The literature has given attention to employer reputation but it's very little known empirically as a corporate phenomenon. The studies are required to be conducted to determine the relation and influence of artificial intelligence based systems in employer reputation (Benitez et al., 2020), including those developed within the knowledge managements systems (Mishchuk et al., 2016; Kot \& Pigoń, 2014). The literature has highlighted various particulars that influence the reputation such as pride, satisfaction, commitment and perception of employees, investors and customers that determine the reputation of firms (Auger et al., 2013; Derun \& Mysaka, 2018). Further, the studies have depicted that firms must focus and involve in environmental concerns that affect workplace and it becomes attractive for potential employment (Jones et al., 2014). The previous study has focused on involvement of women gender that influence the reputation of firms (Iseke \& Pull, 2019).

The emergence of information technology the functions of business management have been altered during data processing to conduct activities based on AI and technological aspects. The functions of business such as management, financial department, operations and HR department have been altered due to electronic means and emergence of technological equipment and AI based systems. The term of electronic recruitment and electronic based HR functions emerged due to its accuracy and speed while reducing cost and incorporated various long-term benefits. The emergence and implementation of AI based functions brings various benefits to business functions such as recruitment process, hiring process while keeping the cost lower and higher quality (Breaugh, 2013).

The present study intends to determine the employer reputation of pharmaceutical industry based on utilization of AI based HR functions including AI recruitment and AI quality that predict AI adoption intention of firms to adopt and implement AI based solutions. The study also intends to determine the mediating role of AI adoption between exogenous and endogenous constructs of study. The study contributes to the body of knowledge by explaining recruitment function of HR under artificial intelligence perspective and quality of function under AI umbrella, the study also contributes to the body of knowledge by mediation role of $\mathrm{AI}$ adoption to predict employer reputation based on AI based recruitment and quality.

The current paper entails the introduction and background, literature review, research methodology, analysis and discussion, and conclusion sections. The paper focused on the employer reputation based on artificial intelligence-based recruitment and quality with mediation role of artificial intelligence adoption among Indonesian pharmaceutical firms.

\section{Literature review}

This section of research study entails the details about employer reputation based on various diverse aspects in different industries and regions of the world. The current study expresses 
the phenomenon of employer reputation, AI based systems that are relevant to HR function that is one of prime factor named recruitment and quality based on AI perspective. This section presents the relationship between AI based recruitment and AI adoption, AI quality and AI adoption, AI adoption and employee reputation, mediating role of AI adoption between AI recruitment and employer reputation and mediation role of AI adoption between AI quality and employee reputation.

\subsection{Artificial intelligence and employer reputation}

The current research study intends to determine the employer reputation of pharmaceutical industry of Indonesia based on AI adoption as mediator influenced by AI based recruitment and AI based quality. The first section presents the relationship between employer reputation and AI adoption by explaining the phenomenon of employer reputation of pharmaceutical industry of Indonesia. The literature has given attention to employer reputation and described that it is not only related to attracting or hiring the potential workforce but also impact the retention level of qualified human capital. The emerging nations has observed attrition and faced it as one of major issue in their industries such as India has observed $30 \%$ annual employee turnover as compare to China with $19 \%$ employee turnover, western countries have faced 5 to $6 \%$ employee turnover ratio as depicted in literature. The higher labor demand impacts the wage rate therefore industry becomes more attractive for potential candidates with higher level of qualification; that also causes the switching of employees from one firm to other due to attractive packages. Employees switch their employers due to attractive salary packages and various other working environmental factors. The frequent employee turnover causes various losses to the firms including negatively effect on productive pace, employee commitment and financial loss with human capital loss as one of major setback (Dögl \& Holtbrügge, 2014; Abadía Alvarado \& De la Rica, 2020; Bibi, 2020; Abdi Zarrin et al., 2020; Abulela \& Davenport, 2020). The firms strive to attract potential candidates and most importantly firms focus to retain their top talented employees that are considered as human capital and important for firms in achievement of goals and objectives strategically and employees retention considered as one of important challenge for firms in today's business world. The global operated firms faced this challenge at higher level as compare to non-global firms, the challenges and issues also includes diverse cultural values and staff management at various business units worldwide. The firms strive to focus on talent management and retention of employees to compete in global market, so therefore multinational firms attract potential candidates around the world with best qualities and talents and develop strategies to retain their employees regardless of their culture and nationality but only based on their talent, knowledge, skills and abilities. The firms focus to retain their knowledge-based employees such as scientists, researchers and engineers as these employees' possess the potential to innovate and contribute towards achievement of goals and objective which further contribute in competitive advantages. The studies have been conducted to assess the critical role of knowledge workers have been played in creating innovative initiatives and to gain competitive advantages. The firms face short of workforce with multi skill employees and face challenges in attracting and acquiring talented employees to compete on global level (Caligiuri et al., 2010; Čančar, 2018; Akin Arikan, 2019). 
The literature has addressed the issue of adoption of AI based solution and technological advancements through well-established innovation diffusion theory and explained that AI adoption is necessary in organizational success. The theory of technology-organization-environment (TOE) has been deployed as well to deeply understand the phenomenon of technology adoption and its influence on performance related outcomes (Alsheibani et al., 2020; Maake \& Tranos, 2019; Adle \& Akdemir, 2019). The studies have been proposed various research frameworks that addressed the role of diverse factors including organization context, technological context and environmental context towards adoption of AI based solution and technological advancements. The study entails top management support, organizational size, organizational readiness and managerial issues under organizational factors towards adoption of AI. The study also examined the role of technological context based on relative advantage and compatibility to determine the AI adoption. The third context examined in the study was environmental context that was judged on the base of competitive pressure and government regulations towards adoption of artificial intelligence based systems (Alsheibani et al., 2020). The previous studies have been examined the role of AI based solution to predict the adoption intention for performance enhancement.

The researcher hasn't come across a single study that empirically examines the relationship and influence between AI adoption and employer reputation. Based on previous studies the current study claims that AI adoption in firms influence the employer reputation. The present study claims to be one of pioneer study that intends to empirically examine the relationship between AI adoption and employer reputation among pharmaceutical industry of Indonesia. The above literature review and objective of study derives towards the following hypothesis:

H1: Artificial Intelligence adoption significantly influence the Employer Reputation among pharmaceutical Industry of Indonesia.

\subsection{Artificial intelligence based recruitment and artificial intelligence adoption and employer}

The emergence of technology and AI based systems has altered the HR processes including recruitment that has improved in performance perspective. The involvement of technology to conduct business processes coined the term electronic recruitment back in 80 s that brings various benefits to the organizations from various perspectives. The e-recruitment facilitates firms to speed-up the process by minimizing cost and time and attracts potential employees around the world. The utilization of corporate website serves for recruitment and facilitate for hiring purposes that fulfills and disseminate the information about available vacancy and opportunities available in firms; there are various websites serve the purpose to hire the appropriate potential employees including Naukri.com, monster.com, careerbuilder.com and etc. around the world as these sites provide the links for currently available positions (Nawaz, 2019).

The literature has expressed the role of information technology in conducting HR functions and introduced various significant benefitted changes at operational level. The internet era has contributed in development of various applications that serves different organizations 
to conduct their business operations at managerial level. It demands relevant managerial competencies to conduct communications with stakeholders via AI based technologies, for instance, in case of e-commerce (Hu et al., 2019). The firms strive to utilize technology based business solutions due to higher effectiveness and efficiency of systems such as internet and AI based solutions provide digitalization aspect to conduct $\mathrm{HR}$, finance and managerial functions to satisfy the customers and fulfill the demand of customers to gain competitive advantages that believed to be develop reputation (Bondarouk et al., 2017). The literature argued that utilization of artificial intelligence brings various benefits to the industry by improving the performance of HR functions through effective recruitment process, through effective training and development strategies, implementation of electronic payroll system, attract and acquire talent which further needed to be retained for competitive advantages based on the unique possessed skills, knowledge and abilities (Nawaz, 2019).

It has been documented and observed practically that newly established technologies have been implemented for effective automation that has replaced the traditional workforce through robotics management. The utilization of technology has replaced the human efforts as automation has the capabilities of human like skills with intelligence based on AI solutions (van der Aalst et al., 2018). The research studies have been conducted to assess the HR management to influence the job satisfaction, description, screening of candidates, hiring, training and development, compensation, performance management and mapping based on implementation of expert systems to conduct business activities. The studies have addressed the need of implementation of IT based solutions and adopted a model for implementing the machine learning and artificial intelligence influence the innovation and increase the level of organizational success (Sadlapur, 2017; Bai et al., 2020; Chang \& Huang, 2020; Abdulateef et al., 2020; Akbar et al., 2020).

The previous study conducted by Nawaz (2019) that determines the employer reputation influenced by AI based HR system as electronic recruitment influence the employer reputation due to utilization of latest technological adoption such as AI based solutions and suggested to develop strategies for adoption and implementation of latest available technology to conduct business activities. The study depicted positive significant relationship between AI based HR management and employer reputation and argued that AI based systems assist in hiring and retaining talented employees around the world and contributes for competitive advantages.

The current study derived the following hypothesis based on above literature:

H2: Artificial Intelligence Recruitment system significantly influence the AI adoption among pharmaceutical Industry of Indonesia

H3: Artificial Intelligence Recruitment system significantly influence the Employer Reputation among pharmaceutical Industry of Indonesia.

\subsection{Artificial intelligence quality and artificial intelligence adoption and employer reputation}

The phenomenon of quality has been discussed extensively in literature and considered as an antecedent to satisfaction of customers and behavior of individuals according to management 
literature. The literature has defied the quality as perception of customers and assessment of customers about services or products offered by individual business entity. The quality depends upon value judgment or environment as tangible and intangible services offered by employees (Shi et al., 2014). The recent years have observed the rapid development of latest technologies included artificial intelligence to serve the community at wider and greater level. The quality of service based on utilization of technologies has been expressed in tourism industry and hospitality industry that found to be contributive in operational excellence and efficiency (Prentice et al., 2019). The artificial intelligence has been adopted and implemented by various organizations in various industries to conduct business activities by utilizing machines, robots and computers while assisting human to perform business management. In the present context, the utilization of AI primarily referred as digital services conducted through machines and robots to satisfy the customers and also facilitate in purchases and consumption. The artificial intelligence plays significant role in services provided to customers for their positive response towards product or services referred as satisfaction which becomes loyal in future that serves as competitive advantages (Lu et al., 2019).

The research studies have been conducted to assess the role of customer relationship management through utilization of electronic management systems for information sharing among customers and participants of business units. The effective CRM based on latest available technologies enable firms to gain loyalty and satisfaction of customers to gain competitive advantages and for accomplishment of long term objectives (Kumar, 2010). The firms invest huge financial amounts to adopt and implement AI based solutions to conduct business functions including marketing, HR, finance department and managerial tasks. The studies have found that investments to adopt and implement latest technologies to conduct business operations bring benefits and worth returns specifically by gaining customer satisfaction which further leads to establish customer loyalty. Appropriate links are proved in various researches in the field of AI and ICT factors influencing business success due to improvement of relationships with customers (Bilan et al., 2019; Nikodemska-Wołowik et al., 2019). The technology based systems influence the services quality in any sector such as tourism industry, banking industry, education industry, hospitality industry and many more for the purpose of customer satisfaction and loyalty (Ganguli \& Roy, 2011; Prentice et al., 2020).

The current study intends to determine the employer reputation based on AI adoption influenced by artificial intelligence-based quality in pharmaceutical industry of Indonesia. The study is novel in empirically investigate the relationship and influence of artificial intelligence-based quality to predict the AI adoption that further leads to gain employer reputation. The study contributes to the body of knowledge by empirically examining the relationship between exogenous and endogenous constructs of study. The above literature derives us to following hypotheses:

H4: Artificial Intelligence Quality significantly influence the AI adoption among pharmaceutical Industry of Indonesia

H5: Artificial Intelligence Quality significantly influence the Employer Reputation among pharmaceutical Industry of Indonesia. 


\subsection{Mediating role of $\mathrm{AI}$ adoption}

The study intends to determine the mediation role of AI adoption between exogenous and endogenous constructs of the study, the literature has been discussed between AI based recruitment function to predict AI adoption; the relationship between AI based quality and AI adoption; the relationship is described between AI adoption and employer reputation. The objective of the study also explained the relationship between AI based recruitment and employer reputation and AI based quality to predict employer reputation. So therefore AI adoption claims to be mediator between exogenous and endogenous constructs as objective of study and to explain the employer reputation among Indonesian pharmaceutical industry.

H6: AI adoption mediate relationship between Artificial Intelligence Recruitment and employer reputation among pharmaceutical Industry of Indonesia

H7: AI adoption mediate relationship between Artificial Intelligence Quality and employer reputation among pharmaceutical Industry of Indonesia.

\subsection{Research framework}

The relationship between the variables are presented in Figure 1 above which depicts the research framework for the empirical analysis which will be discussed below. The next section below outlines the methodology employed to validate the framework which is developed based on the 7 hypothesis proposed as a result of the arguments presented in the literature review.

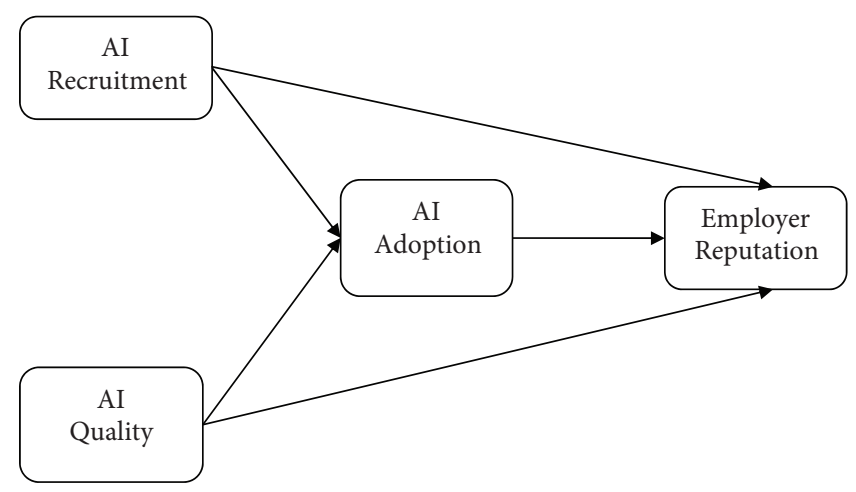

Figure 1. Research framework

\section{Research methodology}

The study was quantitative in nature and was conducted on pharmaceutical industry of Indonesia. The unit of analysis was organization and data was collected through structured questionnaires based on previously developed measurement scale. The purpose of the study was to determine the employer reputation based on AI based systems for human resource management. The study examined the relationship between artificial based recruitment sys- 
tem and AI adoption intention of pharmaceutical firms in Indonesia. The quality based on artificial based solution was also examined in relationship with AI adoption, as the artificial intelligence based systems adoption and implementation is considered as one of major challenge in highly competitive business environment. The study also empirically examined the relationship between artificial intelligence based system and artificial intelligence quality to predict the employer reputation. The study also intended to empirically examine the mediation role of AI adoption between AI recruitment and AI quality to predict employer reputation. The analysis was conducted based on collected data form pharmaceutical industry of Indonesia that has developed HR system based on AI application or technological aspects. The current study collected data from 50 leading pharmaceutical firms through email in Indonesia for data collection based on convenience sampling as currently situation is getting worse due to pandemic covid-19 issue. The sample was drawn and 350 responses from these firms; but in total 193 completed responses were received.

\section{Analysis and results}

The study incorporated Smart-PLS for data analysis to determine the relationship between exogenous and endogenous constructs of study as proposed in research framework. The analysis phase consists of two sections including measurement model and structure equation model. The measurement model consists of construct reliability and validity, further the discriminant validity is also determined under measurement model. The second phase of analysis entails the hypothesized relationship investigation between proposed constructs of framework; the structural equation model investigates the relationship between constructs based on statistical grounds including $\beta$ value, $t$-value and $p$-value.

\subsection{Measurement model}

The first section of the analysis considers measurement model to investigate the reliability and validity of constructs by utilizing the Smart-PLS. The PLS algorithm was used for determining the construct validity and reliability. The Table 1 presents the Cronbach Alpha, composite reliability and average variance extracted (AVE) to examine the construct reliability and validity. It has been established that value for Cronbach alpha, composite reliability and Average variance extracted (AVE) must remain higher than $0.70,0.70$ and 0.50 respectively according to (Hair et al., 2014). The Figure 2 below presents the measurement model assessment model generated in PLS through algorithm method for assessing the reliability and validity of the constructs.

The above Table 1 demonstrates construct reliability and validity based on Cronbach alpha, composite reliability and average variance extracted (AVE), the table presents that Cronbach alpha for Artificial Intelligence Quality (AIQ), Artificial Intelligence Recruitment (AIRec), Artificial Intelligence adoption (Aladopt) and Employer Reputation (ER) observed to be $0.902,0.782,0.938$ and 0.817 respectively. Therefore it satisfies the condition for acceptable Cronbach alpha. The values for composite reliability observed to be $0.931,0.842$, 0.956 and 0.881 respectively and satisfy the condition of acceptable composite reliability. The 
Table 1. Measurement model

\begin{tabular}{|l|c|c|c|}
\hline & Cronbach's Alpha & Composite Reliability & Average Variance Extracted (AVE) \\
\hline AIQ & 0.902 & 0.931 & 0.773 \\
\hline AIRec & 0.782 & 0.842 & 0.516 \\
\hline Aiadopt & 0.938 & 0.956 & 0.844 \\
\hline ER & 0.817 & 0.881 & 0.650 \\
\hline
\end{tabular}

Note: Artificial intelligence recruitment (AIRec), Artificial intelligence quality (AIQ), Artificial Intelligence adoption (Aladopt), Employee reputation (ER).

Average variance extracted (AVE) found to be $0.773,0.516,0.844$ and 0.650 that satisfy the condition for acceptable AVE as it was established to be higher than 0.50 . The results depicted that all constructs of the study found to be reliable and valid based on statistical values.

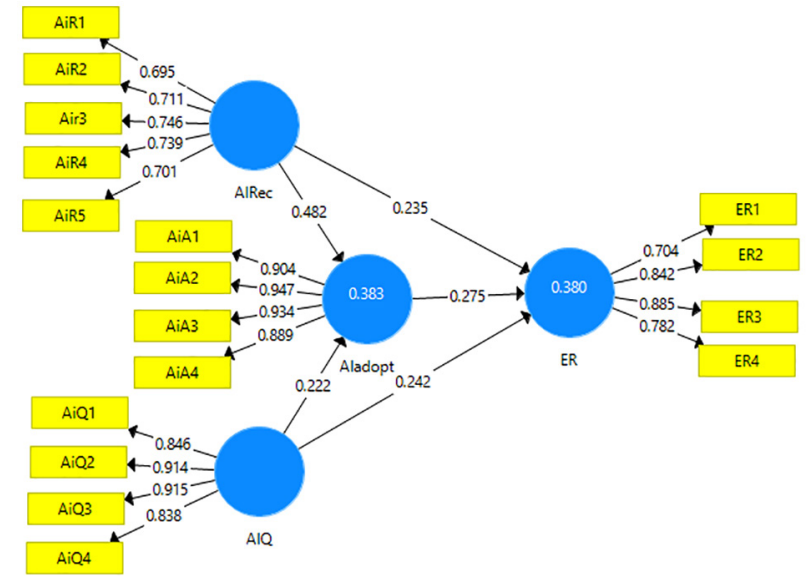

Note: Artificial intelligence recruitment (AIRec), Artificial intelligence quality (AIQ), Artificial Intelligence adoption (AIadopt), Employee reputation (ER).

Figure 2. Measurement model

The above Figure 2 demonstrate the measurement model of the framework generated through the PLS algorithm to examine the Cronbach alpha, composite reliability and average variance extracted. However the above stated figure presents the factor loading of items of each construct. The factor loading of each construct found to be above cutoff point of 0.40 , hence retained all the items. The variables of the framework are measured on the base of items, the artificial intelligence recruitment is measured on the base of five items included AiR1, AiR2, AiR3, AiR4 and AiR5, the construct artificial intelligence quality is measured based on four items included AiQ1, AiQ2, AiQ3 and AiQ4, similarly four items of artificial intelligence adoption included AiA1, AiA2, AiA3 and AiA4 and four items of employee reputation including ER1, ER2, ER3 and ER4. 


\subsection{Discriminant validity}

This section of study determines the convergent validity of constructs based on collected data through PLS algorithm in measurement model. The convergent validity determine the correlation between same and alternative constructs, the previous section of analysis showed reliability and validity of that presents internal consistency. The discriminant validity is actually the square root of AVE that must be higher than the correlation between constructs. It has been established statistically in previous studies that square root of average variance must be significant than its correlation with other constructs of AVE and should exceed inter-construct correlations according to (Fornell \& Larcker, 1981). The Table 2 presents the discriminant validity:

Table 2. Discriminant validity

\begin{tabular}{|l|c|c|c|c|}
\hline & AIQ & AIRec & Aiadopt & ER \\
\hline AIQ & 0.879 & & & \\
\hline AIRec & 0.476 & 0.718 & & \\
\hline Aiadopt & 0.451 & 0.587 & 0.919 & \\
\hline ER & 0.478 & 0.512 & 0.523 & 0.806 \\
\hline
\end{tabular}

Note: Artificial intelligence recruitment (AIRec), Artificial intelligence quality (AIQ), Artificial Intelligence adoption (AIadopt), Employee reputation (ER).

The above Table 2 demonstrates the discriminant validity and it is clear from the table that correlation among same variable found to higher than correlation with other variables of same proposed framework.

\subsection{Structural equal model (SEM)}

This section of the study entails the investigation of hypothesized relationship as depicted in literature review and hypotheses were developed. The analysis of seven hypotheses was developed and this section investigated the relationship between constructs. The bootstrapping method was used to determine the relationship between construct to investigate the hypothesized relationship. The Figure 3 presents the model of structural equation and demonstrates the significant values between the constructs of the framework.

\subsection{Direct relationship}

This section presents the direct relationship investigation, the hypothesis $\mathrm{H} 1$ investigated the relationship between artificial intelligence adoption and employer reputation, the hypothesis $\mathrm{H} 2$ was investigated between artificial intelligence recruitment and artificial intelligence adoption; the hypothesis $\mathrm{H} 3$ investigated the relationship between artificial intelligence recruitment and employer reputation. The objective of the study also investigated the relationship between independent variables and dependent variable. The hypothesis $\mathrm{H} 4$ examined the relationship between artificial intelligence quality and artificial intelligence adoption, 
similarly the hypothesis $\mathrm{H} 5$ investigated the relationship between artificial intelligence quality and employer reputation. The mediating role of AI adoption was also one of objective of the current study, so H6 and H7 determined the mediating role of AI adoption between AI recruitment and employer reputation, AI quality and employer reputation respectively. The relationship is examined the relationship based on $\beta$ value that presents the direction of relationship and t-value must remain higher than 1.96 with $5 \%$ error margin (Hair et al., 2014). The Table 3 demonstrated the results of direct hypotheses.

Table 3. Direct hypothesis

\begin{tabular}{|l|c|c|c|}
\hline & Original Sample $(\mathrm{O})$ & T Statistics (O/STDEV) & p-values \\
\hline AIQ -> AIadopt & 0.222 & 2.972 & 0.003 \\
\hline AIQ -> ER & 0.242 & 3.285 & 0.001 \\
\hline AIRec -> AIadopt & 0.482 & 7.993 & 0.000 \\
\hline AIRec -> ER & 0.235 & 3.175 & 0.002 \\
\hline Aiadopt -> ER & 0.275 & 3.434 & 0.001 \\
\hline
\end{tabular}

Hypothesis H1: investigated the relationship between AI adoption and employer reputation; the results of the study show that $\beta$ value 0.275 , $t$-value was observed to 3.434 with p-value as 0.001 the result satisfies the statistical condition for acceptability.

Hypothesis $\mathrm{H} 2$ : the $\mathrm{H} 2$ investigated the relationship between AI recruitment and AI adoption and results show that $\beta$ value for relationship observed to be 0.482 and t-value as 7.993 with p value 0.000 ; based on statistical values the result of $\mathrm{H} 2$ accepted as significant.

Hypothesis H3: the $\mathrm{H} 3$ investigated the relationship between AI recruitment and employer recruitment and results show that $\beta$ value for relationship observed to be 0.235 and $\mathrm{t}$-value as 3.175 with p value 0.002 ; based on statistical values the result of $\mathrm{H} 3$ accepted as significant.

Hypothesis H4: the $\mathrm{H} 4$ investigated the relationship between AI quality and AI adoption and results show that $\beta$ value for relationship observed to be 0.222 and $t$-value as 2.972 with $\mathrm{p}$ value 0.003 ; based on statistical values the result of $\mathrm{H} 4$ accepted as significant.

Hypothesis H5: the H5 investigated the relationship between AI quality and employer reputation and results show that $\beta$ value for relationship observed to be 0.242 and $t$-value as 3.285 with p value 0.001 ; based on statistical values the result of H5 accepted as significant.

\subsection{Mediating relationship}

The Table 4 presents the mediating relationship and role of AI adoption between exogenous and endogenous constructs; the hypothesis $\mathrm{H} 6$ investigated the relationship between AI recruitment and employer reputation with mediation effect of AI adoption. The hypothesis H7 investigated the mediating role of AI adoption between AI quality and employer reputation.

The Table 4 demonstrates the mediation relationship between independent and dependent variables and mediation by AI adoption. The H6 investigated the relationship between 
Table 4. Mediating relationship

\begin{tabular}{|l|c|c|c|}
\hline & Original Sample (O) & T Statistics (O/STDEV) & p-values \\
\hline AIQ -> AIadopt-> ER & 0.061 & 2.158 & 0.031 \\
\hline AIRec $>$ A Aladopt -> ER & 0.133 & 2.921 & 0.004 \\
\hline
\end{tabular}

AI recruitment and employer reputation mediation by AI adoption, the result of $\mathrm{H} 6$ demonstrates that $\beta$ value observed to be 0.133 and $t$-value observed to be 2.921 with $p$ value 0.004 ; so therefore hypothesis $\mathrm{H} 6$ accepted statistically. The hypothesis $\mathrm{H} 7$ investigated the mediating relationship and effect of AI adoption between AI quality and employer reputation. The $\beta$ value observed to be 0.061 , the t-value found to be 2.158 with p-value as 0.031 ; that satisfy the statistical conditions. So therefore, H6 and H7 reported as statistically significant.

\subsection{Model results}

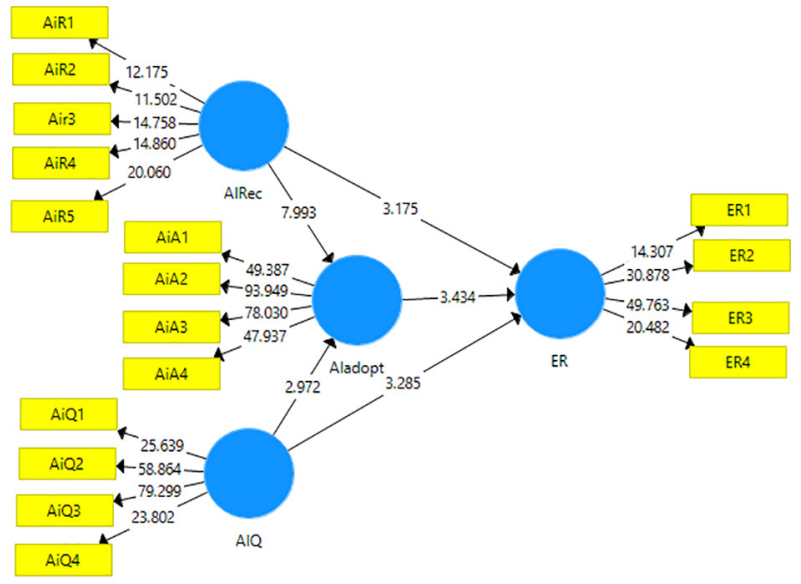

Note: Artificial intelligence recruitment (AIRec), Artificial intelligence quality (AIQ), Artificial Intelligence adoption (AIadopt), Employee reputation (ER).

Figure 3. Structural equation model results

The above Figure 3 demonstrates the structural equation model (SEM) and determined the relationship between constructs of framework; the t-value is occurred between the relationships of each constructs that shows the significance of the all relationships.

\section{Summary of results}

This study has intended to analyze the impact of AI recruitment, AI quality along with the mediating impact of AI adoption on the employer reputation. The study findings have been provided through measurement model and structural model findings. It is observed that both reliability and validity of the measurement model constructs are found to be significant for the consideration for PLS-SEM findings. The main finings are summarized in Table 5 below. 
The results indicate that all hypotheses are accepted. Initially direct impact of AI recruitment and AI quality on employer reputation is examined. It is observed that AI recruitment and AI quality have shown their significant and positive impact on employer reputation under full sample consideration. Similarly, there is a significant and positive impact of AI adoption on ER. Additionally, the mediating impact of AI adoption between AIQ and ER and between AIREC and ER is found to be positively significant at 5 percent. This would employ that all the direct and indirect research hypotheses have been accepted.

Table 5. Summary of results

\begin{tabular}{|c|c|c|}
\hline Hypotheses & Relationship & Results \\
\hline $\mathrm{H} 1$ & AIadopt $\rightarrow$ ER & Accepted \\
\hline $\mathrm{H} 2$ & AIR $\rightarrow$ AIadopt & Accepted \\
\hline H3 & AIR $\rightarrow$ ER & Accepted \\
\hline H4 & AIQ $\rightarrow$ AIadopt & Accepted \\
\hline H5 & AIQ $\rightarrow$ ER & Accepted \\
\hline H6 & AIR $\rightarrow$ Aladopt $\rightarrow$ ER & Accepted \\
\hline H7 & AIQ $\rightarrow$ AIadopt $\rightarrow$ ER & Accepted \\
\hline
\end{tabular}

\section{Conclusions}

The current research study determined the employer reputation based on artificial intelligence solution among Indonesian pharmaceutical industry. The study expressed the role of artificial based human resource functions to define the employer reputation. The important phenomenon of artificial intelligence adoption and implementation is considered in the current study to define the relationship and role of AI based HR function. The study determined the employer reputation based on utilization of artificial intelligence to conduct the HR functions. The study is novel in explaining and empirically examining the role of AI based recruitment and quality to determine the employer reputation with mediation role of artificial intelligence adoption. The study was conducted on pharmaceutical industry of Indonesian and found that AI based recruitment significantly influence the AI adoption and employer reputation. The study found statistically significant relationship between AI quality and AI adoption and employer reputation. The mediation effect of AI adoption was also observed between exogenous and endogenous constructs of the study. In nutshell, all direct and mediating hypothesized relationships were found to be statistically significant and it has been suggested for pharmaceutical industry of Indonesia to adopt artificial intelligencebased solutions to conduct business functions. There is lack of AI based solution studies to determine the business management constructs such as marketing management, customer relationship and financial management.

There are limitations to every research, while conducting current research various limitations have been faced in terms of cost and time constraints, the spread of corona virus and inclined pandemic disease was one of the most crucial limitations as lockdown situation prevent to visit the industry or for data collection researcher has to relay on online informa- 
tion and emails for questionnaire responses. The future research can be conducted to implement the AI based solutions for effective supply chain management and longitudinal research design may be adopted to overcome the time limitation with pre- and post-assessment of implementation of AI based solutions for business operations.

\section{References}

Abadía Alvarado, L. K., \& De la Rica, S. (2020). The evolution of the gender wage gap in Colombia: 1994 and 2010. Cuadernos de Economía, 39(81), 857-895.

https://doi.org/10.15446/cuad.econ.v39n81.73820

Abdi Zarrin, S., Gracia, E., \& Paixão, M. P. (2020). Prediction of academic procrastination by fear of failure and self-regulation. Educational Sciences: Theory and Practice, 20(3), 34-43.

Abdulateef, M. H., Hadi, F. F., Alwan, A. H., \& Abd, A. N. (2020). Sewage water treatment of chemistry department in college of science - Diyala University. Systematic Reviews in Pharmacy, 11(12), 119-123.

Abulela, M. A. A., \& Davenport, E. C. (2020). Measurement invariance of the learning and study strategies inventory-second edition (Lassi-ii) across gender and discipline in egyptian college students. Educational Sciences: Theory and Practice, 20(2), 32-49. https://doi.org/10.12738/jestp.2020.2.003

Adle, A. A., \& Akdemir, Ö. (2019). Achieving competitive advantage in technology based industry: How developing intellectual capital matters. International Journal of eBusiness and eGovernment Studies, 11(2), 89-103. https://doi.org/10.34111/ijebeg.20191121

Akbar, F. H., Pasiga, B. D., Samad, R., Rivai, F., Abdullah, A. Z., Awang, A. H., Pasinringi, S. A., Saleh, L. M., Irwandy, \& Pratiwi, D. (2020). The relationship between service quality, culture similarity to satisfaction and loyalty of medical (dental) tourism. Systematic Reviews in Pharmacy, 11(12), 19-30.

Akin Arikan, C. (2019). A comparison of Kernel equating methods based on neat design. Eurasian Journal of Educational Research, 82, 27-44. https://doi.org/10.14689/ejer.2019.82.2

Alsheibani, S., Cheung, Y, \& Messom, C. (2020). Re-thinking the competitive landscape of artificial intelligence. In Proceedings of the $53^{\text {rd }}$ Hawaii International Conference on System Sciences (pp. 58615870). https://doi.org/10.24251/HICSS.2020.718

Altounjy, R., Alaeddin, O., Hussain, H. I., \& Kot, S. (2020). Moving from bricks to clicks: Merchants' acceptance of the mobile payment in Malaysia. International Journal of eBusiness and eGovernment Studies, 12(2), 136-150. https://doi.org/10.34111/ijebeg.202012204

Auger, P., Devinney, T. M., Dowling, G. R., Eckert, C., \& Lin, N. (2013). How much does a companys reputation matter in recruiting? MIT Sloan Management Review, 54(3), 23.

Auriacombe, C. J., \& Sithomola, T. (2020). The use of participatory action research in a participative democracy: In critique of mechanisms for citizen participation. The International Journal of Social Sciences and Humanity Studies, 12(1), 50-65.

Babikova, K., \& Bucek, J. (2019). A model replication with an extension of students' perception of prospective employer attractiveness. Journal of Competitiveness, 11(2), 5-21. https://doi.org/10.7441/joc.2019.02.01

Bai, Y., Wang, Y., Li, Y., \& Liu, D. (2020). Influence of exercises of different intensities on adolescent depression. Revista Argentina de Clinica Psicologica, 29(1), 417-422.

https://doi.org/10.24205/03276716.2020.57

Basheka, B. C., \& Auriacombe, C. J. (2020). Barriers to women's participation in public procurement in Africa: Empirical evidence from Uganda. The International Journal of Social Sciences and Humanity Studies, 12(2), 222-237. https://www.kab.ac.ug/publication/barriers-to-womens-participation-inpublic-procurement-in-africa-empirical-evidence-from-uganda/ 
Benitez, J., Ruiz, L., Castillo, A., \& Llorens, J. (2020). How corporate social responsibility activities influence employer reputation: The role of social media capability. Decision Support Systems, 129, 113223. https://doi.org/10.1016/j.dss.2019.113223

Berejena, T., Kleynhans, I. C., \& Vibetti, S. P. (2020). Economic impacts of the rotational policy on the food handlers in the national school nutrition programme in gauteng province. International Journal of Economics and Finance Studies, 12(2), 520-533. https://www.sobiad.org/eJOURNALS/journal_IJEF/archieves/IJEF-2020-2/t-berejena.pdf

Bibi, S. (2020). The Anti-Blanchard model and structural change in Latin America: An analysis of Chile, Argentina and Mexico. Cuadernos de Economía, 39(80), 499-522. https://doi.org/10.15446/cuad.econ.v39n80.83267

Bilan, Y., Mishchuk, H., Samoliuk, N., \& Grishnova, O. (2019). ICT and economic growth: Links and possibilities of engaging. Intellectual Economics, 13(1), 93-104. https://doi.org/10.13165/IE-19-13-1-07

Bondarouk, T., Parry, E., \& Furtmueller, E. (2017). Electronic HRM: Four decades of research on adoption and consequences. The International Journal of Human Resource Management, 28(1), 98-131. https://doi.org/10.1080/09585192.2016.1245672

Breaugh, J. A. (2013). Employee recruitment. Annual Review of Psychology, 64, 389-416. https://doi.org/10.1146/annurev-psych-113011-143757

Caligiuri, P., Colakoglu, S., Cerdin, J.-L., \& Kim, M. S. (2010). Examining cross-cultural and individual differences in predicting employer reputation as a driver of employer attraction. International Journal of Cross Cultural Management, 10(2), 137-151. https://doi.org/10.1177/1470595810370890

Chang, Y., \& Huang, J. (2020). Impacts of intergenerational care for grandchildren and intergenerational support on the psychological well-being of the elderly in China. Revista Argentina de Clinica Psicologica, 29(1), 57-64. https://doi.org/10.24205/03276716.2020.8

Čančar, E. (2018). Social media and everyday politics; Tim Highfield. Croatian International Relations Review, 24(82), 142-145. https://hrcak.srce.hr/index.php?show=clanak\&id_clanak_jezik=296008

Derun, I., \& Mysaka, H. (2018). Stakeholder perception of financial performance in corporate reputation formation. Journal of International Studies, 11(3), 112-123.

https://doi.org/10.14254/2071-8330.2018/11-3/10

Dlalisa, S. F., \& Govender, D. W. (2020). Challenges of acceptance and usage of a learning management system amongst academics. International Journal of eBusiness and eGovernment Studies, 12(1), 63-78. https://doi.org/10.34111/ijebeg.202012105

Dögl, C., \& Holtbrügge, D. (2014). Corporate environmental responsibility, employer reputation and employee commitment: An empirical study in developed and emerging economies. The International Journal of Human Resource Management, 25(12), 1739-1762. https://doi.org/10.1080/09585192.2013.859164

Fornell, C., \& Larcker, D. F. (1981). Evaluating structural equation models with unobservable variables and measurement error. Journal of Marketing Research, 18(1), 39-50. https://doi.org/10.2307/3151312

Ganguli, S., \& Roy, S. K. (2011). Generic technology-based service quality dimensions in banking: Impact on customer satisfaction and loyalty. International Journal of Bank Marketing, 29(2), 168-189. https://doi.org/10.1108/02652321111107648

Hair, Jr J. F., Sarstedt, M., Hopkins, L., \& G. Kuppelwieser, V. (2014). Partial least squares structural equation modeling (PLS-SEM) An emerging tool in business research. European Business Review, 26(2), 106-121. https://doi.org/10.1108/EBR-10-2013-0128

Hu, X., Ocloo, C. E., Akaba, S., \& Worwui-Brown, D. (2019). Effects of business to business e-commerce adoption on competitive advantage of small and medium-sized manufacturing enterprises. Economics and Sociology, 12(1), 80-99. https://doi.org/10.14254/2071-789X.2019/12-1/4 
Iseke, A., \& Pull, K. (2019). Female executives and perceived employer attractiveness: On the potentially adverse signal of having a female CHRO rather than a female CFO. Journal of Business Ethics, 156(4), 1113-1133. https://doi.org/10.1007/s10551-017-3640-1

Jones, D. A., Willness, C. R., \& Madey, S. (2014). Why are job seekers attracted by corporate social performance? Experimental and field tests of three signal-based mechanisms. Academy of Management Journal, 57(2), 383-404. https://doi.org/10.5465/amj.2011.0848

Kot, S., \& Pigoń, Ł. (2014). Effective occupational counselling for the unemployed. Polish Journal of Management Studies, 10(1), 54-62. https://www.researchgate.net/publication/270090209_Effective_occupational_counselling_for_the_unemployed

Kumar, V. (2010). A customer lifetime value-based approach to marketing in the multichannel, multimedia retailing environment. Journal of Interactive Marketing, 24(2), 71-85. https://doi.org/10.1016/j.intmar.2010.02.008

Lu, L., Cai, R., \& Gursoy, D. (2019). Developing and validating a service robot integration willingness scale. International Journal of Hospitality Management, 80, 36-51. https://doi.org/10.1016/j.ijhm.2019.01.005

Maake, B. M., \& Tranos, Z. (2019). A serendipitous research paper recommender system. International Journal of Business and Management Studies, 11(1), 39-53.

Mishchuk, H., Bilan, Y., \& Pavlushenko, L. (2016). Knowledge management systems: Issues in enterprise human capital management implementation in transition economy. Polish Journal of Management Studies, 14(1), 163-173. https://econpapers.repec.org/article/pczjournl/v_3a14_3ay_3a2016_3ai_3a1_3ap_3a163-173.htm

Nawaz, N. (2019). Artificial Intelligence interchange human intervention in the recruitment process in Indian software industry. International Journal of Advanced Trends in Computer Science and Engineering, 8(4), 1433-1442. https://doi.org/10.30534/ijatcse/2019/62842019

Nikodemska-Wołowik, A. M., Bednarz, J., \& Foreman, J. R. (2019). Trends in young consumers' behaviour - implications for family enterprises. Economics and Sociology, 12(3), 11-24. https://doi.org/10.14254/2071-789X.2019/12-3/1

Pachura, A. (2019) Talents, projects and management - Attempt at synthesis. Polish Journal of Management Studies, 19(1), 271-282. https://doi.org/10.17512/pjms.2019.19.1.21

Prentice, C., Dominique Lopes, S., \& Wang, X. (2019). Emotional intelligence or artificial intelligence an employee perspective. Journal of Hospitality Marketing \& Management, 29(4), 377-403. https://doi.org/10.1080/19368623.2019.1647124

Prentice, C., Dominique Lopes, S., \& Wang, X. (2020). The impact of artificial intelligence and employee service quality on customer satisfaction and loyalty. Journal of Hospitality Marketing \& Management, 29(7), 739-756. https://doi.org/10.1080/19368623.2020.1722304

Rozsa, Z., \& Kmecová, I. (2020). Cybervetting prospective employees of SMEs. Journal of International Studies, 13(1), 295-309. https://doi.org/10.14254/2071-8330.2020/13-1/19

Sadlapur, S. (2017). Information literacy of management students in Mumbai metropolitan area. Tilak Maharashtra Vidyapeeth. http://hdl.handle.net/10603/173712

Shi, Y., Prentice, C., \& He, W. (2014). Linking service quality, customer satisfaction and loyalty in casinos, does membership matter? International Journal of Hospitality Management, 40, 81-91. https://doi.org/10.1016/j.ijhm.2014.03.013

van der Aalst, W. M. P., Bichler, M., \& Heinzl, A. (2018). Robotic process automation. Business \& Information Systems Engineering, 60, 269-272. https://doi.org/10.1007/s12599-018-0542-4 